\title{
The Effect Of Lpdp Scholarship Program Towards Performance In Alumni Scholarship Recipients
}

\author{
Aditya Aldy Nugraha ${ }^{1}$, Niken Ardiyanti ${ }^{2}$ \\ \{adityaldy@gmail.com ${ }^{1}$, nardiyanti@yahoo.com ${ }^{2}$ \} \\ Universitas Indonesia, Jakarta ${ }^{1}$, Universitas Indonesia, Jakarta ${ }^{2}$
}

\begin{abstract}
LPDP plays an important role in supporting one of the government's priority programs, namely building the quality of Indonesian human resources as a donor of higher education scholarships. However, studies on the effect of LPDP scholarships on the performance of LPDP scholarship alumni have not been done much. The purpose of this study was to determine the effect of nationalism and transformational leadership of LPDP alumni on the performance of alumni of LPDP scholarship recipients mediated by job satisfaction. Data on 597 respondents were collected through online surveys and analyzed using CB-SEM. The test results show that nationalism and transformational leadership can influence performance by mediating job satisfaction. The results of this study provide information about managerial practices that can be carried out by the Institute to be able to maximize the potential of alumni.
\end{abstract}

Keywords: LPDP alumni, nationalism, transformational leadership, job satisfaction, job performance

\section{Introduction}

The Education Fund Management Institution (LPDP) is an Indonesian Government Education scholarship institution that was established in 2012. Based on data obtained from the LPDP Alumni Division, from a total of 6,435 alumni up to semester 1 of 2019 there were 5,942 alumni currently employed. Under the Indonesian government's priority programs, in its objectives, the focus and the LPDP program are focused on developing the quality of human resources in various fields that support the acceleration of Indonesian development.

Government-sponsored scholarships can provide maximum benefits for individuals, entrepreneurs, and the community so that government scholarship programs become important for policy practices that support state development [1]. Furthermore, the scholarship program can increase one's interest and motivation to be able to apply the abilities or knowledge they gain when studying and can increase their confidence in their respective places or fields of work due to the scholarship program he received [2].

According to Kreitner \& Kinicki [3], an increase in a person's performance can be influenced by perceived job satisfaction so that he can work with full individual capacity. Based on Ahlerup \& Hansson's [4] research which discusses the importance of national development and nationalism for the nation's performance, it can be seen in the form of national pride. Furthermore, Shang \& Jang's [5] research results show that national pride has a positive influence on satisfaction.

Based on Sadeghi \& Pihie's research [6], the most influential leadership style on one's job satisfaction is the transformational leadership style. Furthermore, in the research of Manzoor et al., [7] which discusses transformational leadership that affects performance, also in 
research conducted by Tafvelin, Hasson, Holmström, \& von Thiele Schwarz [8], that leadership training will benefit job satisfaction and performance.

\section{Research Questions}

From the identification results of the problems above, regarding the importance of achievment LPDP through the performance of LPDP scholarship alumni, and the limitation of research regarding government scholarship alumni, encouraging the author to research the effect of providing nationalism and transformational leadership in the departure preparation program on the performance of the LPDP scholarship program alumni with a focus on research questions:

a) Do nationalism and transformational leadership influence job satisfaction of LPDP scholarship alumni?

b) Do nationalism and transformational leadership influence the performance of LPDP scholarship alumni?

c) Does job satisfaction affect the performance of LPDP scholarship alumni?

\section{Literature Review}

\subsection{Nationalism}

Nationalism is an ideology in which members of a nation have a duty to be loyal to the nation and emphasize the primacy of the nation's welfare. Nationalism also refers to the attitudes that members of a nation have when they think of themselves, and the actions they take when they determine the fate of their own nation [9].

Based on Ahlerup \& Hansson's [4] research that discusses the importance of national development and nationalism for the nation's performance, a successful nation-building process has several aspects, namely that citizens feel bound together by a sense of togetherness, that they speak, understand, and trust each other as well they identify themselves and are proud of the nation. Empirical evidence that the effectiveness of nationalism on the nation's performance is largely absent and therefore nationalism can be explained by the national pride variable with items taken from WVS, namely (1) "How proud are you to be Austrian?", And (2) "I see myself as a part of my local community. This study found that the level of nationalism, measured by the level of national pride, could not support the effectiveness of the nation's performance. Furthermore, Shang \& Jang's research [5] revealed the relationship between national identity and national pride in life satisfaction in South Korea. The results show that national pride has a positive influence on life satisfaction, but empirical evidence rarely shows the relationship between national identity and life satisfaction. In another study, Gangl [10] stated that public institutions are better at presenting national achievements or national achievements than national symbols to enhance citizen cooperation and the pride that citizens feel (national pride). So that this research has the following hypothesis:

H1: Nationalism influences the job satisfaction of LPDP scholarship alumni H2: Nationalism influences the performance of LPDP scholarship alumni 


\subsection{Transformational Leadership}

Leadership is defined as a social influence process in which leaders seek the voluntary participation of subordinates in an effort to achieve organizational goals. A more formal definition, leadership is defined as the ability of an individual to influence, motivate, and enable others to contribute to the effectiveness and success of the organizations of which they are members. At the individual level, leadership involves mentoring, coaching, inspiration and motivation. A leader builds teams, creates cohesion and resolves conflicts at the group level. Finally, leaders build culture and create change at the organizational level [11]. Among various leadership styles, previous research has shown that transformational leadership has a greater impact on job satisfaction compared to other leadership approaches [12].

In research Sadeghi \& Pihie [6] discuss leadership styles that affect job satisfaction. Among the three visible leadership styles, transformational and transactional leadership styles are positively related to job satisfaction while laissez-faire is negatively correlated with job satisfaction. In the research conducted by Tafvelin, Hasson, Holmström, \& von Thiele Schwarz [8] stated in the study, that leadership training will provide benefits for formal leaders and informal leaders. This is marked by an increase in transformational leadership for informal leaders who work as engineers after they have received transformational leadership training. Furthermore, the promotion of transformational leadership may be influenced by the organization in which it is located or located. In research Manzoor et al., [7] discusses transformational leadership that influences job satisfaction and CSR mediation mechanisms on the relationship of transformational leadership and job performance. The results show that transformational leadership is positive and fully predicts job performance. Specifically, this study found that CSR significantly mediated the effect of transformational leadership on performance. So that this research has the following hypothesis:

H3: Transformational leadership influences job satisfaction of LPDP scholarship alumni H4: Transformational leadership influences the performance of LPDP scholarship alumni

\subsection{Job Satisfaction and Job Performance}

Job satisfaction, a concept that is widely studied in individual behavior research within an organization, is generally conceptualized as an affective variable resulting from an assessment of work experience. In simpler terms, job satisfaction is the degree to which people like their jobs [13]. The importance of studying job satisfaction in organizational behavior research is associated with its positive correlation with performance, which in turn drives organizational performance [14]. An employee who is very satisfied with his job must outperform his fellow who is dissatisfied. Previous research states that employees who have high satisfaction tend to pay more attention to work time (time), make fewer mistakes (quality), be more productive (quantity), and have a strong intention to stay in the organization [15].

Based on the research of Yu et al. [16] Job satisfaction and self-efficacy can mediate the relationship between training supplies and whistle-blowing. Based on Bernanthos research, [17] shows that leadership and motivation have a positive and significant impact on job satisfaction. Leadership has a positive and direct effect on employee performance, then motivation has a positive and significant direct effect on employee performance. Job satisfaction has a positive and significant effect directly on employee performance, leadership has a positive and significant effect indirectly on employee performance through job satisfaction. Leadership and motivation have positive and significant indirect impacts on employee performance through job satisfaction. So that this research has the following hypothesis: 
H5: Job satisfaction influences the performance of LPDP scholarship alumni

\section{Method}

\subsection{Research Design}

This study is a modification of 8 previous studies, which looked at the effect of nationalism on job satisfaction of Shang and Jang [5] and performance [4]. Then the effect of transformational leadership affects job satisfaction [6], [8] and performance [7]. As well as job satisfaction on performance [16], [17]. So that the research model used by the author in this study is by the following picture of the research framework:

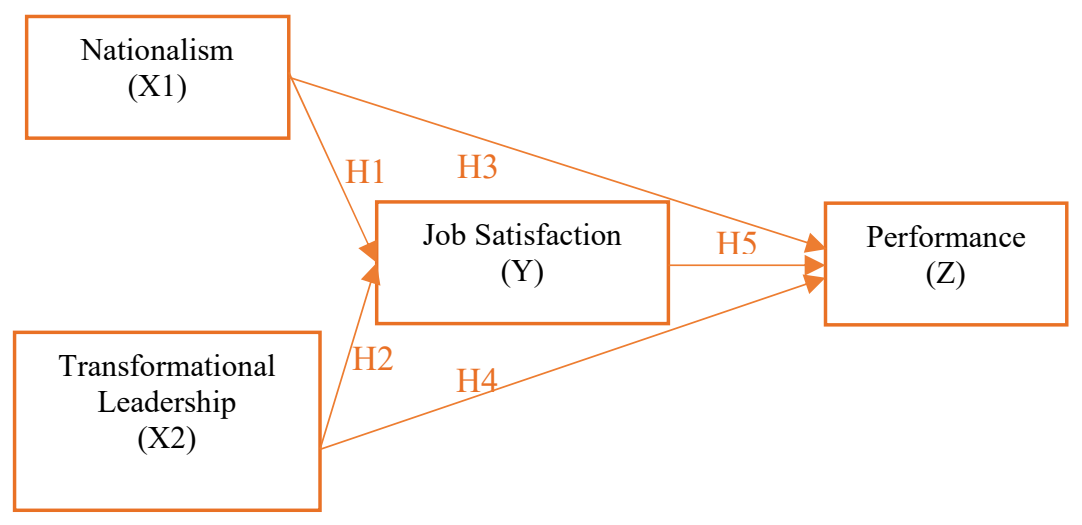

Fig.1. Research Design

\subsection{Research Instruments}

Confirmatory research has the aim to test hypotheses and relationships between variables [18]. The research uses a confirmatory research design by considering that the purpose of this study is to test hypotheses that have been tested in previous studies. In the questionnaire prepared, there are questions and statements in closed form. Participants were asked to fill out a questionnaire with a six-point Likert scale $(1=$ Strongly disagree; $6=$ Strongly agree $)$ for all variables of this study. A scale with points without a midpoint can better capture the opinion of respondents than a point scale that has a middle value [19].

\subsection{Population and sample}

The population in this study is the LPDP scholarship program alumni. The sample used is some alumni who are expected to represent the population. Determination of the amount of sample data needed in this study uses the minimum size requirement, which must be equal to or greater than 5-10 times the number of formative indicators used to measure one constructor ten times the number of the largest structural paths directed at a particular construction on a 
structural model [20] The number of indicators used in this study was 38 indicators, so the minimum number of research respondents was 190-380 respondents.

\subsection{Data Analysis Method}

A validity test is done to find out and test a measuring instrument whether used in this study has been able to measure what must be measured [18] This study uses a validity test with Kaiser Meyer Olkin (KMO) using the SPSS 25 application.

The reliability test is carried out to find out whether the measuring instrument used in the study shows the level of accuracy, accuracy, stability, or consistency in expressing certain symptoms even though they are carried out at different times [18]. This test is carried out on statements that have been declared valid. In this study, using Cronbach's Alpha Technique using the SPSS 25 application.

The structural model test is the relationship between the independent latent variable and the dependent latent variable. In this study, a Goodness of Fit test was conducted which in principle aims to find out whether a data distribution from a sample follows a certain theoretical distribution or not [20]. Hair et.al. [20] grouped the existing Goodness of Fit into three parts namely absolute fit measures, incremental fit measures, and parsimonious fit measures.

The estimated goodness of fit structural model test criteria can be met, then the next step is an analysis of the structural model relationships (hypothesis testing). The relationship between constructs in the hypothesis is shown by the value of regression weights which if shows a number below 0.05 or $5 \%$ can be interpreted as having a significant effect [20].

\section{Result And Discussion}

\subsection{Pre-Test}

Based on the pre-test results, it can be seen that the questionnaire indicator on each variable has a value in the KMO component matrix $\geq 0.5$. In addition, the Cronbach's alpha value obtained is also $\geq 0.6$, so that all indicators of nationalism, transformational leadership, job satisfaction, and performance variables have met the requirements and are declared valid and reliable for use in main research.

\subsection{Main-Test}

Standardized Loading Factor (SLF). The rule of thumb is SLF $\geq 0.60$ is acceptable [20]. Based on the results of processing it turns out that the loading factor of all indicators is more than 0.60 after the removal of TL13 and TL14 items. Thus it can be concluded that all indicators are declared valid and have good convergent validity.

Construct Reliability (CR). If the value of construct reliability on each latent variable is greater than 0.7 , this shows that each indicator has consistency in measuring the latent variable respectively, or shows good reliability [20]. Based on the results of calculations on all variables have a construct reliability value $>0.70$, meaning that each indicator has consistency in measuring their respective latent variables.

Average Variance Extracted (AVE). The default is if the AVE value is greater than 0.5, it can be said that the latent variable has good convergent validity. This means that latent 
variables can explain an average of more than half the variance of the indicators [20]. Based on calculations, all latent variables have AVE values $>0.50$. This shows that the latent variables used in the study already have good convergent validity.

The goodness of Fit Index (GOF). The calculation results show that the size of the goodness of fit of the RMR, PGFI, and PNFI is at a value that has the results of a good fit, which means it has a good match value, ie an RMR value of 0.066, PGFI of 0.654 and PNFI of 0.065 . Whereas the size of the suitability of the RMSEA, TLI, NFI, RFI, IFI, and CFI models have marginal values, while for the Chi-Square, GFI, and AGFI model compatibility values have a poor or poor fit value. However, based on Hair et al., [20] said that from several model feasibility tests conducted, the model is said to be feasible if at least one of the model's feasibility test methods is met. That way, it can be concluded that the model in this study is fit and can be tested in the next stage.

\subsection{Hypothesis testing}

H1: Nationalism (X1) influences job satisfaction (Y) LPDP scholarship alumni.

The positive influence between $\mathrm{X} 1$ to $\mathrm{Y}$ there is a p-value of $0.014(<0.05)$ then Ho is rejected, meaning Nationalism (X1) has a significant positive effect on job satisfaction (Y) of LPDP scholarship program alumni at a significance level of $5 \%$.

H2: Nationalism (X1) influences the performance of (Z) LPDP scholarship alumni The positive influence between $\mathrm{X} 1$ to $\mathrm{Z}$ there is a p-value of $0.095(>0.05)$ then Ho is accepted, meaning Nationalism (X1) has no significant effect on the performance (Z) of LPDP scholarship program alumni at a significance level of $5 \%$.

H3: Transformational leadership (X2) influences job satisfaction (Y), alumni of the LPDP scholarship program,

The positive influence between $\mathrm{X} 2$ on $\mathrm{Y}$ there is a p-value of $0,000(<0.05)$ then Ho is rejected, meaning that transformational leadership (X2) has a significant positive effect on job satisfaction $(\mathrm{Y})$ of LPDP scholarship program alumni at a significance level of $5 \%$.

H4: Transformational leadership (X2) influences the performance (Z) of LPDP scholarship program alumni

The positive influence between $\mathrm{X} 2$ on $\mathrm{Z}$ there is a p-value of $0,000(<0.05)$ then Ho is rejected, meaning that transformational leadership (X2) has a significant positive effect on the performance (Z) of LPDP scholarship program alumni at a significance level of 5\%.

H5: Job satisfaction $(Y)$ influences the performance $(Z)$ of LPDP scholarship program alumni

The positive effect between $\mathrm{Y}$ and $\mathrm{Z}$ there is a p-value of $0,000(<0.05)$ then Ho is rejected, meaning that job satisfaction $(\mathrm{Y})$ gives a significant positive effect on the performance $(\mathrm{Z})$ of LPDP scholarship program alumni at a significance level of $5 \%$.

\section{Conclusions}

\subsection{Implications}

Nationalism is proven to be able to have an impact on the job satisfaction of alumni in their respective places and fields of work. This means that alumni are satisfied with their field of work which can also have a positive impact on a sense of nationalism in developing the 
country. This must always be maintained by the quality of program delivery in each year. However, nationalism does not influence work performance. This could have happened because of pride in the achievements of the country or the state of the country does not exist, so it did not affect their performance. This might be overcome by providing additional nationalism briefing material so that it can influence the performance of alumni in their respective workplaces.

Transformational leadership is proven to be able to have an impact on job satisfaction and performance of alumni in their respective places and fields of work. This means that alumni are satisfied with their field of work so that they can implement the spirit of transformational leadership in their workplace following the briefing that has been undertaken. This must always be maintained by the quality of program delivery in each year. Job satisfaction can influence the performance of alumni in their respective places. This shows that the satisfaction of alumni with their work can affect their performance, in this case, the Institute can make alumni job satisfaction as a reference to the performance of alumni in their respective workplaces.

\subsection{Limitations}

This research was conducted based on the self-rating of LPDP scholarship recipients, making it very possible for biases against the results of the study. The short duration of the study resulted in a limited number of respondents, from the current 6,435 alumni but only 597 alumni who were willing to fill in the questionnaire, so the study sample could not describe the overall condition of LPDP scholarship recipients. The use of online media as a means of distributing questionnaires was chosen and carried out due to the difficulty in doing face-toface meetings so that filling in questionnaires became more vulnerable.

\subsection{Future Studies}

Based on the results of the limitations of this study, the following suggestions can be given by the author for further research: Retrieve population data for all LPDP scholarship alumni more broadly so that the sample can represent the condition of LPDP scholarship alumni in general. In the LPDP scholarship program there are 3 major phases namely, pre-study, study period, and post-study with each phase there are several programs such as the pre-study phase there are administrative selection programs, computer-based selection, interview selection, and departure preparation program (PK). Then during the study phase, there is an evaluation program during the study. Then in the post-study phase, there is a program of re-orientation, talent management, and alumni management. In this study, the authors only focus on the prestudy phase with the departure preparation program (PK). So that there is room for further research on the effect of the LPDP scholarship program on the performance of its alumni.

\section{References}

[1] L. W. Perna, K. Orosz, and Z. Jumakulov, "Understanding the human capital benefits of a government-funded international scholarship program: An exploration of Kazakhstan's Bolashak program,” Int. J. Educ. Dev., 2015, doi: 10.1016/j.ijedudev.2014.12.003.

[2] D. L. Sjoquist and J. V. Winters, "The effect of Georgia's HOPE scholarship on college major: a focus on STEM," IZA J. Labor Econ., 2015, doi: 10.1186/s40172-015-0032-6.

[3] R. Kreitner and A. Kinicki, "Perilaku Organisasi Organizational Behavior," in 1, 2014. 
[4] P. Ahlerup and G. Hansson, "Nationalism and government effectiveness," J. Comp. Econ., 2011, doi: 10.1016/j.jce.2011.05.001.

[5] S. E. Ha and S. J. Jang, "National Identity, National Pride, and Happiness: The Case of South Korea," Soc. Indic. Res., 2015, doi: 10.1007/s11205-014-0641-7.

[6] Sadeghi, A., \& Pihie, Z. (2012). Transformational Leadership and Its Predictive Effects on Leadership Effectiveness. International Journal of Business \& Social Science.

https://doi.org/10.1016/j.sbspro.2011.11.341

[7] Manzoor, F., Wei, L., Nurunnabi, M., Subhan, Q. A., Shah, S. I. A., \& Fallatah, S. (2019). The impact of transformational leadership on job performance and CSR as mediator in SMEs. Sustainability (Switzerland). https://doi.org/10.3390/su11020436

[8] Tafvelin, S., Hasson, H., Holmström, S., \& von Thiele Schwarz, U. (2019). Are Formal Leaders the Only Ones Benefitting From Leadership Training? A Shared Leadership Perspective.

Journal of Leadership and Organizational Studies. https://doi.org/10.1177/1548051818774552

[9] Standford University. (2013). Behaviorism Stanford Encyclopedia of Philosophy. Stanford Encyclopedia of Philosophy.

[10] Gangl, K., Torgler, B., \& Kirchler, E. (2016). Patriotism's Impact on Cooperation with the State: An Experimental Study on Tax Compliance. Political Psychology. https://doi.org/10.1111/pops.12294

[11] Sinding, K., \& Waldstrom, C. (2014). Organisational Behaviour, Fifth Edition. http://www.ncbi.nlm.nih.gov/pubmed/2616327

[12] ÇOĞALTAY, N., YALÇIN, M., \& KARADAĞ, E. (2016). Educational Leadership and Job Satisfaction of Teachers: A Meta-Analysis Study on the Studies Published between 2000 and 2016 in Turkey. Eurasian Journal of Educational Research. https://doi.org/10.14689/ejer.2016.62.13

[13] Spector, P. E. (2006). Method variance in organizational research: Truth or urban legend? Organizational Research Methods. https://doi.org/10.1177/1094428105284955

[14] Lannoo, S., \& Verhofstadt, E. (2016). What drives the drivers? Predicting turnover intentions in the Belgian bus and coach industry. Transportation Research Part A: Policy and Practice. https://doi.org/10.1016/j.tra.2016.06.024

[15] Sánchez-Beaskoetxea, J., \& Coca García, C. (2015). Media image of seafarers in the Spanish printed press. Maritime Policy and Management. https://doi.org/10.1080/03088839.2014.925593

[16] Yu, H., A. Sirsat, S., \& Neal, J. A. (2019). Linking food safety training with whistle-blowing: The mediation roles of job satisfaction and self-efficacy. International Journal of Contemporary Hospitality Management. https://doi.org/10.1108/IJCHM-10-2017-0689

[17] Bernanthos, B. (2018). The direct and indirect influence of leadership, motivation and job satisfaction against employees' performance. European Research Studies Journal. https://doi.org/10.35808/ersj/998

[18] Sekaran, U., \& Bougie, R. (2016). Research Method for Business. In John Wiley \& Sons Ltd. https://doi.org/10.1017/CBO9781107415324.004

[19] Hempton, R. W. and B. M., \& Komives, J. P. D. and S. R. M. (2008). Cultural Differences: Why Do Asians Avoid Extreme Responses? Survey Practice. https://oi.org/10.29115/sp-20080011

[20] Hair, J. F., Black, W. C., Babin, B. J., \& Anderson, R. E. (2014). Pearson New International Edition: Multivariate Data Analysis. In Pharmaceutical Quality by Design: A Practical Approach. 